\title{
Regional treatment of hepatic micrometastasis by adenovirus vector-mediated delivery of interleukin-2 and interleukin-12 cDNAs to the hepatic parenchyma
}

\author{
Edward A. Hirschowitz, ${ }^{1}$ Hassan A. Naama, ${ }^{2}$ Denis Evoy, ${ }^{1,2}$ Michael D. Lieberman, ${ }^{2}$ \\ John Daly, ${ }^{2}$ and Ronald G. Crystal ${ }^{1}$
}

${ }^{1}$ Division of Pulmonary and Critical Care Medicine and ${ }^{2}$ Department of Surgery, New York Hospital-Cornell Medical Center, New York, New York 10021.

\begin{abstract}
We hypothesize that adenovirus (Ad) vector-mediated delivery of the human interleukin-2 (IL-2) cDNA (AdIL2) or the murine IL-12 cDNA heterodimer (AdIL12) would produce high concentrations of cytokines in the local hepatic milieu to induce host responses sufficient to inhibit the growth of experimental colon carcinoma-derived hepatic metastases. Ad vectors administered intravenously, which is a route known to deliver $>90 \%$ of the vector to the hepatic parenchyma, achieved significant levels of each cytokine locally, with minimal levels in the sera. To examine the therapeutic effect, the AdIL2 and AdIL12 vectors were evaluated in a hepatic metastasis model that was established by injecting $3 \times 10^{4}$ cells from the poorly immunogenic syngeneic C26 colon carcinoma cell line into the right lobe of the livers of BALB/C mice. Animals received AdIL2, AdIL12, or control virus ( $10^{8}$ plaque-forming units each) intravenously for 2 days after tumor implantation, and tumor growth was compared with naive controls. The AdNull control tumors measured $116 \pm 25 \mathrm{~mm}^{2}$ at 2 weeks. The control virus showed no significant antitumor effect. In marked contrast, both AdIL2 and AdIL12 vectors that were delivered regionally had significant antitumor effects, with AdIL2-treated animals having an average tumor size of $16 \pm 8 \mathrm{~mm}^{2}$; AdIL12-treated tumors measured $6 \pm 6 \mathrm{~mm}^{2}(P<.01$, both compared with control). Both the AdIL2 and AdIL12 vectors provided a significant survival advantage by log-rank analysis $(P<.01)$, but only AdIL12 translated into an increase in mean survival from 27 (naive control) to 37 days. To evaluate whether these antitumor effects were T-cell-mediated, splenocytes from AdIL2-treated, AdIL12-treated, and naive control groups were stimulated in vitro with $\gamma$-irradiated C26 tumor cells for 5 days and tested for C26 tumor cell cytolysis by an in vitro cytotoxicity assay. Splenocytes from both AdIL2- and AdIL12-treated animals showed a dose-dependent, T-cell-mediated, specific cytolysis of CT26 cells. AdIL12 and to a lesser extent AdIL2 induced natural killer cell activity, as determined by a dose-dependent increase in lysis of the natural killer-specific target cell YAC-1. Overall, these data suggest that regional Ad-mediated delivery of IL-2 and IL-12 cDNAs may be useful for local tumor control and may warrant further investigation as a potentially useful adjuvant for the treatment of hepatic micrometastasis.
\end{abstract}

Key words: Adenovirus; interleukin-2; interleukin-12; liver; tumor.

$I^{\mathrm{n}}$ mmunotherapy for metastatic cancer is directed toward stimulating host defenses to recognize and destroy tumor cells. ${ }^{1}$ There are two general approaches to immunotherapy: (a) activation of the immune system to identify specific antigens related to tumors and (b) the nonspecific, general activation of immune effector cells. ${ }^{2}$ Although the specific activation approach has the elegance of a "surgical strike," it is limited by the requirement of identification of tumor-specific epitopes and by the heterogeneity of tumor antigens in a polyclonal population of tumor cells. ${ }^{1,2}$ In contrast, nonspecific

Received December 1, 1998; accepted April 3, 1999.

Address correspondence and reprint requests to Dr. Edward A. Hirschowitz, New York Hospital-Cornell Medical Center, 520 East 70th Street, ST505, New York, NY 10021. E-mail address: geneticmedicine@mail.med.cornell.edu

(C) 1999 Stockton Press 0929-1903/99/\$12.00/+0 activation of the immune system avoids the requirement of knowledge of specific antigens but suffers from the problem of nonspecific systemic toxicity.

In vivo gene therapy is one strategy to limit the toxicities of nonspecific immune-activating mediators by directing genes to a localized area so that the gene product is concentrated in the local milieu, achieving sustained high local concentrations of cytokine, with limited systemic exposure. This approach also offers the theoretical potential for an induction of systemic immunity ("in situ vaccination"), similar to approaches using tumor cells transduced with cytokine genes ex vivo as tumor vaccines, to achieve immune enhancement in the proximity of tumor antigens. ${ }^{3,4}$ Most experimental strategies using in vivo gene transfer of cytokine genes target tumor cells directly. ${ }^{5-19}$ An alternate approach is to deliver the therapeutic gene to the normal parenchyma of an organ in which the tumor cells are growing. ${ }^{20}$ One 
such application might be microscopic hepatic metastases from colon cancer, a logical target because $30 \%$ of all individuals with colon cancer will develop liver metastases within 3 years of initial diagnosis. ${ }^{21,22}$ The current study evaluates such a regional approach to cytokine gene therapy for the treatment of hepatic micrometastases.

Interleukin-2 (IL-2) and IL-12 are both rational choices for organ-directed in vivo gene therapy because of their well-defined immunological profiles and based on the knowledge that the recombinant proteins for each have been used clinically with encouraging results; however, both IL-2 and IL-12 are associated with lifethreatening toxicities when administered systemically. ${ }^{23-30} \mathrm{IL}-2$ is the primary cytokine responsible for the activation and clonal expansion of $\mathrm{CD}^{+}$cytotoxic $\mathrm{T}$ lymphocytes (CTLs), which are the primary effector cells that target tumors in an antigen-specific manner. ${ }^{2}$ IL-12 functions to activate and clonally expand natural killer (NK) cells, which kill tumors in a major histocompatibility complex (MHC)-independent fashion. ${ }^{31} \mathrm{IL}-12$ also has a direct effect on $\mathrm{CD}^{+}$lymphocytes $^{31,32}$ and induces $\mathrm{T}$ helper 1 interferon- $\gamma$ secretion, with a resulting augmentation of CTL activity, increasing antigen presentation via unregulated MHC class II on the surface of antigen-presenting cells, and in some cases, MHC class I on the surface of tumor cells. ${ }^{33}$ Although not used clinically for colon carcinoma, both IL-2 and IL-12 have been shown to be effective against experimental colonderived tumors. ${ }^{7,11,34-37}$

In the context of these considerations, the present study compares the local antitumor effects and overall survival following adenovirus (Ad)-mediated regional delivery of human IL-2 cDNA and murine IL-12 cDNA to the hepatic parenchyma of mice with established micrometastases derived from a syngeneic colon carcinoma cell line. The data suggest the involvement of a tumor cell-specific cytotoxic T-cell mechanism and a possible role for antigen-independent (NK cell) antitumor mechanisms.

\section{MATERIALS AND METHODS}

\section{Ad vectors}

The E1a ${ }^{-}$, partial E1b ${ }^{-}$, and partial E3 ${ }^{-}$Ad vector AdIL2 was constructed using the recombination plasmid pCMV.S2 ${ }^{+}$and the Ad5 pJM17 backbone, as described previously. ${ }^{38}$ The AdIL2 vector expression cassette contains the cytomegalovirus immediate early promoter followed by an artificial splice sequence, human IL-2 cDNA (a gift of Bernd Gansbacher, Memorial Sloan-Kettering Cancer Center, New York, NY), and the simian virus 40 polyadenylation sequence. The AdIL12 vector (a gift of Frank Graham, McMaster University, Hamilton, Ontario, Canada) expresses the p35 and p40 subunits of murine IL-12 under the control of the cytomegalovirus promoter; ${ }^{39}$ the vector was tested for production of a functional IL-12 protein. ${ }^{39}$ The AdCD vector, carrying the Escherichia coli cytosine deaminase (CD) cDNA, served as a control virus, because the $\mathrm{CD}$ transgene is not therapeutically active unless combined with the prodrug 5-fluorocytosine. ${ }^{40}$ All vectors were amplified and titered as described previously. ${ }^{41}$

\section{Cell line}

The colon carcinoma cell line C26 is a weakly immunogenic, chemically induced tumor syngeneic to BALB/c mice (National Institutes of Health Division of Cancer Treatment, National Cancer Institute, Frederick, Md). ${ }^{34}$ The cell line was maintained in Dulbecco's modified Eagle's medium (Life Technologies, Grand Island, NY) with $10 \%$ fetal bovine sera (Biofluids, Rockville, Md), $50 \mathrm{U} / \mathrm{mL}$ penicillin $\mathrm{G}$, and $50 \mathrm{mg} / \mathrm{mL}$ streptomycin (Biofluids).

\section{AdIL2- and AdIL12-directed production of human IL-2} in vivo

To evaluate the regional liver delivery of cytokines after systemic administration of Ad vectors, AdIL2 $\left(10^{8}\right.$ plaqueforming units (PFU); $n=3)$, AdIL12 (10 $\left.{ }^{8} \mathrm{PFU} ; n=3\right)$, or naive control $(n=3)$ were delivered intravenously (i.v.) to $\mathrm{BALB} / \mathrm{c}$ mice. At 72 hours, the livers were removed and homogenized in protein lysis buffer $(10 \mathrm{mM}$ tris(hydroxymethyl)aminomethane- $\mathrm{HCl}(\mathrm{pH} 7.4), 2 \%$ Triton X-100, $0.025 \%$ sodium azide, $0.14 \mathrm{M} \mathrm{NaCl}, 1 \mathrm{mM}$ phenylmethylsulfonyl fluoride, $30 \mu \mathrm{M}$ leupeptin, $30 \mu \mathrm{M}$ aprotinin, and $30 \mu \mathrm{M}$ pepstatin; Sigma, St. Louis, Mo) using a Polytron homogenizer. Total protein was quantified using a BioRad protein assay (Hercules, Calif). IL-2 and IL-12 tissue levels were quantified per milligram of protein using enzyme-linked immunosorbent assays (ELISAs) (human IL-2 from R\&D Systems, Minneapolis, Minn; murine IL-12 from Genzyme, Cambridge, Mass). To assess whether there was a significant systemic leak of IL-2 or IL-12 from the liver into the systemic circulation after vector administration to the liver, blood samples taken at the time of sacrifice by right heart puncture were evaluated for levels of IL-2 or IL-12 per milliliter of serum by ELISA, as described above.

\section{Animal model}

Intrahepatic tumors were established by injecting $5 \times 10^{4} \mathrm{C} 26$ cells suspended in a $30-\mu \mathrm{L}$ volume through a 30 -gauge needle into the left hepatic lobe via laparotomy. With this approach, the development of tumors is consistent, resulting in the development of macroscopic tumors $\left(20-40 \mathrm{~mm}^{2}\right)$ at 7 days. Tumor area (width $\times$ length, $\mathrm{mm}^{2}$ ) was measured using calipers. ${ }^{42}$

The i.v. delivery of Ad vectors leads to infection primarily $(>90 \%)$ of liver parenchyma; ${ }^{43,44}$ thus, i.v. delivery of Ad vectors can be used as a paradigm for "regional therapy" in hepatic tumor models. Ad vectors AdIL2 $\left(10^{8} \mathrm{PFU} ; n=5\right)$ or AdIL12 $\left(10^{8} \mathrm{PFU} ; n=5\right)$ or the AdCD control virus ( $10^{8}$ PFU; $n=5)$ were injected in a $100-\mu \mathrm{L}$ volume into the lateral tail of mice at 2 days after tumor cell implantation. A fourth group of animals receiving no therapy served as an additional control $(n=5)$. Tumor burden was assessed at 14 days. To evaluate survival after therapy, mice receiving tumor implantation were subgrouped to receive i.v. AdIL2 $\left(10^{8} \mathrm{PFU} ; n=12\right)$, AdIL12 $\left(10^{8} \mathrm{PFU} ; n=12\right)$, the AdCD control virus $\left(10^{8} \mathrm{PFU} ; n=11\right)$, or no therapy $(n=24)$ and followed for survival for $\leq 150$ days.

\section{Cytotoxic T-cell activity after AdIL12 and AdIL2} delivery in vivo

To determine whether regional AdIL2 or AdIL12 therapy induced specific CTLs, tumors were established as described above; mice were grouped to receive i.v. AdIL2 $\left(10^{8} \mathrm{PFU}\right)$ $(n=3)$, AdIL12 $\left(10^{8} \mathrm{PFU}\right)(n=3)$, or no therapy $(n=3)$ at 2 days after tumor cell implantation as described above. Mice 
A. IL-2

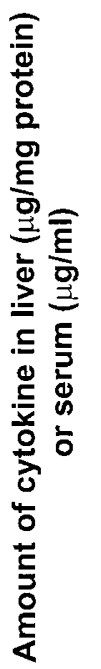

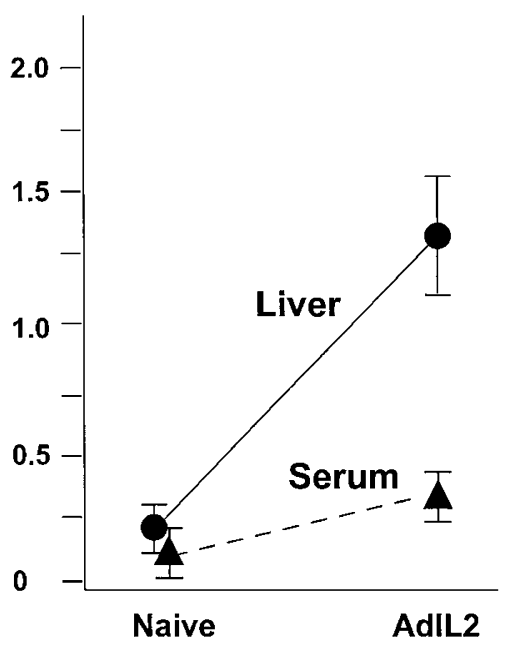

B. IL-12

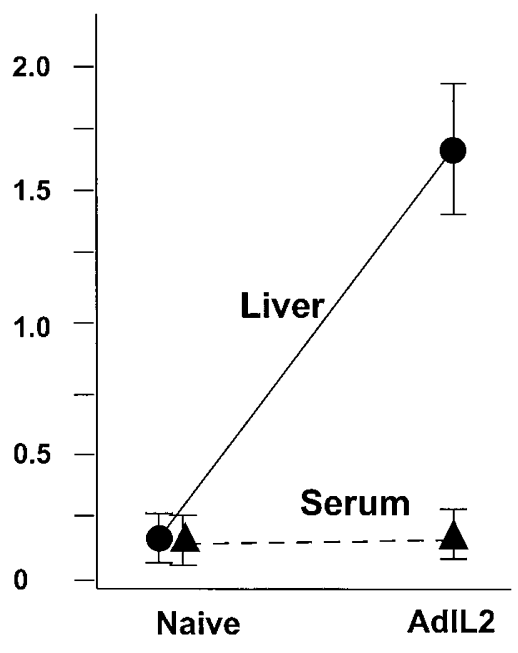

Figure 1. Ad-mediated IL-2 and IL-12 levels in the liver parenchyma and sera after regional delivery of AdIL2 and AdIL12. Ad vectors were delivered i.v., and the levels of each respective cytokine were measured in the liver and sera by ELISA and compared with naive controls. A: IL-2. B: IL-12. For both cytokines, the liver data are expressed in micrograms per milligrams of protein; serum data are expressed as micrograms per milliliter. Data represent the mean \pm SE.

were sacrificed at 12 days after vector delivery, and splenic mononuclear cells were isolated as described previously. ${ }^{45}$ Briefly, spleens harvested from each group were minced and ground, sheared with a 19-gauge needle, and passed through a $200-\mu \mathrm{m}$ mesh to remove fibrous tissue. Live lymphocytes were separated from dead cells and red blood cells using FicollPaque (Pharmacia, Piscataway, NJ) density separation, washed, and resuspended in Dulbecco's modified Eagle's medium. Prepared splenocytes were stimulated in vitro for 5 days with $\gamma$-irradiated (50 Gy) C26 cells. The tumor-specific CTL activity in the cultured, primed splenocytes from each group was quantified using a lactate dehydrogenase (LDH) release cytotoxicity assay (Promega, Madison, Wis) against C26 target cells by coincubating effector and target cells at various ratios $(6: 1-100: 1)$ for 4 hours at $37^{\circ} \mathrm{C}$ in serum-free medium. LDH was assayed in the supernatant by optical density (OD) at $490 \mathrm{~nm},{ }^{46}$ and target cell lysis was calculated as follows: $100 \times([\mathrm{OD}$ of sample $-\mathrm{OD}$ of spontaneous release of $\mathrm{LDH}$ from target cells - OD of spontaneous release of LDH from effector cells]/[OD of maximal release from target cells - OD of spontaneous release from target cells]). ${ }^{46}$

\section{NK activity}

Splenocytes from mice at 7 days after i.v. injection of AdIL12 $\left(10^{8}\right.$ PFU, $\left.n=3\right)$, AdIL2 (10 8 PFU, $\left.n=3\right)$, AdCD control virus $\left(10^{8} \mathrm{PFU}, n=3\right)$, or naive control $(n=3)$ were evaluated for cytolysis of YAC-1 murine hybridoma cells (American Type Culture Collection, Manassas, Va), which serve as a specific target for NK cells. ${ }^{47}$ Splenocytes were harvested from the animals in each group and pooled; mononuclear cells were isolated as described above. Fresh, pooled splenocytes from each group were incubated with $10^{4}$ YAC-1 cells in increasing effector to target (E:T) cell ratios $(0: 1,10: 1$, and 100:1) for 4 hours at $37^{\circ} \mathrm{C}$ in serum-free medium. LDH was assayed in the supernatant by OD, and target cell lysis was calculated as described for the CTL assay.

\section{Statistical analysis}

Data are presented as mean \pm SEM. All comparisons were made using an unpaired two-tailed Student's $t$ test. Survival advantage was measured using the log-rank test.

\section{RESULTS}

Ad-mediated liver production of IL-2 and IL-12

To evaluate the production of IL-2 and IL-12 within the hepatic parenchyma following a single dose, the systemic delivery of AdIL2 or AdIL12, IL-2, and IL-12 was quantified at 72 hours in the liver and compared with naive controls. The livers of AdIL12-treated mice contained large amounts of IL-2 $(P<.01$ compared with naive controls; Fig 1); the livers of AdIL12-treated mice contained large amounts of IL-12 $(P<.01$ compared with naive controls). In contrast, the AdIL2-treated animals had only a minor increase in sera IL-2 levels, which were not significantly different from the controls $(P=.5)$. Sera from AdIL12-treated animals contained IL-12 levels similar to the naive controls $(P>.1)$. These observations demonstrate that there is local production of the therapeutic cytokines within the liver after administration of the relevant Ad vector, although the pharmacokinetic levels of tissue are undoubtably complex.

\section{Antitumor activity of regionally delivered AdIL2 and AdIL 12}

Syngeneic CT26 colon carcinoma cells grow in the liver in a reproducible manner, with tumors of $100-130 \mathrm{~mm}^{2}$ growing in 14 days (Fig 2). The tumors grew to a 


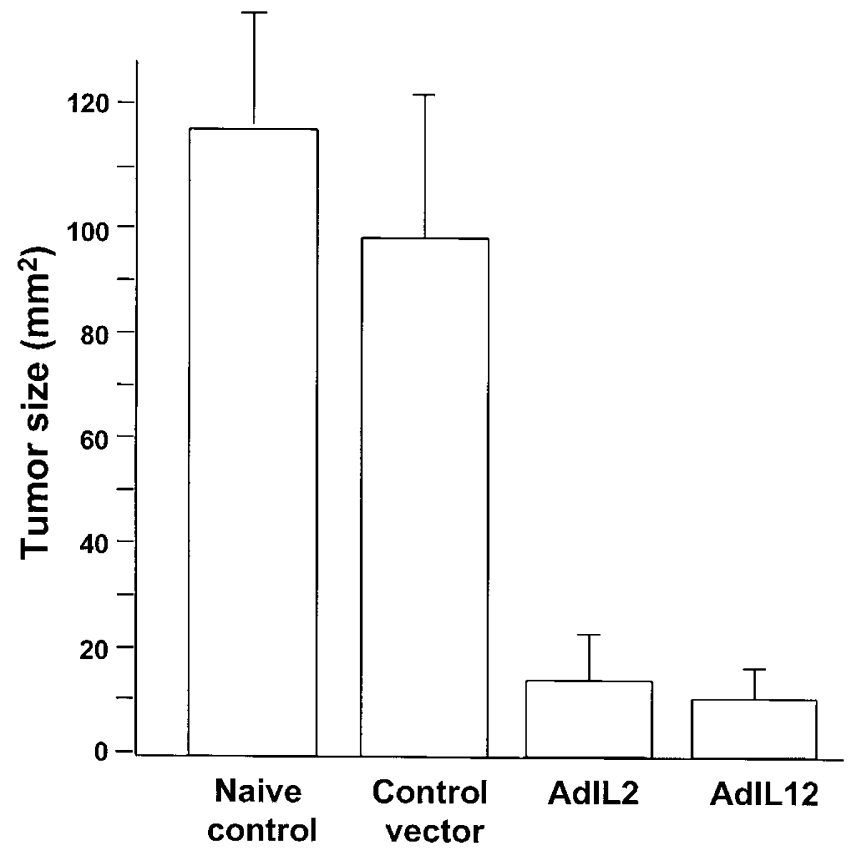

Figure 2. Therapeutic effects of Ad-mediated regional expression of IL-2 and IL-12. Hepatic micrometastases of CT26 syngeneic colon carcinoma cells were established in BALB/c mice, and mice were subgrouped to receive AdIL2, AdIL12, control virus, or no therapy at 2 days after tumor cell implantation. Tumor size was measured in two dimensions, and data are expressed as tumor area $\left(\mathrm{mm}^{2}\right) \pm \mathrm{SE}$ at 14 days.

comparable size in mice receiving the control vector $(P>.1)$. In contrast, mice receiving AdIL2 had a marked clearance in liver tumor burden $(P<.01)$, as did mice receiving AdIL12 $(P<.01)$. There was no differ- ence in the tumor burden of the animals receiving AdIL2 or AdIL12 $(P>.1)$.

\section{Median survival}

To evaluate whether the reduction in tumor burden at 2 weeks translated into a survival advantage, mice were grouped as described above and monitored until death (Fig 3). The median survival of naive mice (24 days) was similar to that for mice receiving the control vector $(27$ days). The median survival of the mice receiving AdIL2 was 28 days. AdIL12 increased the mean survival to 38 days. Although the mean increase in survival after AdIL2 therapy was marginal, both AdIL2 and AdIL12 therapies provided a statistically significant survival advantage as measured by log-rank analysis $(P<.01$ for both AdIL2 and AdIL12 compared with the control). There was one apparent cure ( $\geq 150$ days) in the AdIL2treated group.

\section{Cytotoxic T-cell activity after AdIL12 and} AdIL2 delivery

To assess whether regional delivery of AdIL2 and AdIL12 to liver-bearing micrometastases was capable of inducing specific T-cell-mediated immunity, splenocytes from AdIL2-treated animals, AdIL12-treated animals, and "untreated tumor-bearing" controls were tested for C26 tumor cell-specific cytolysis. Splenocytes from both AdIL2- and AdIL12-treated animals showed a dosedependent T-cell-mediated response, indicating that both vectors are capable of inducing T-cell immunity when delivered in vivo in the milieu of micrometastatic disease (Fig 4).

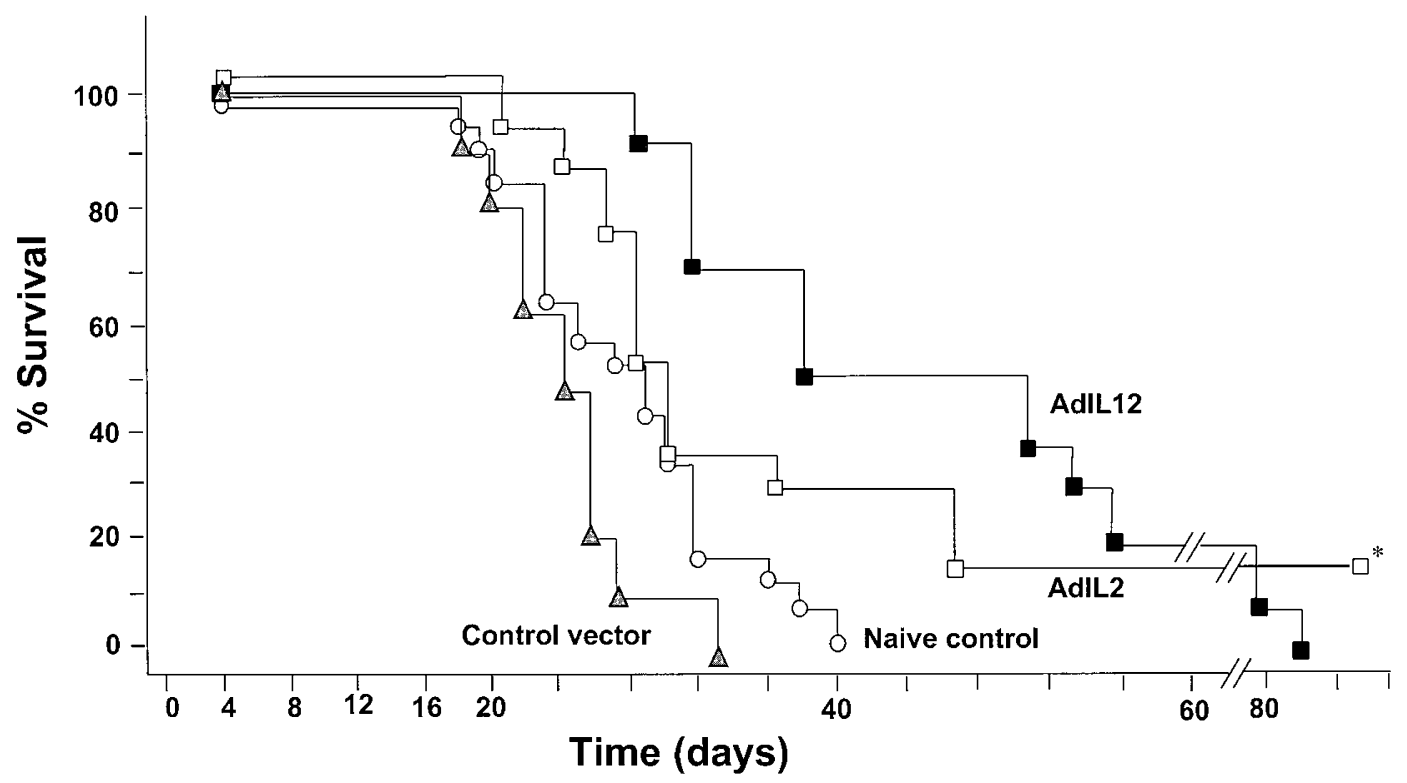

Figure 3. Survival of mice after Ad-mediated regional expression of IL-2 and IL-12. Mice received therapeutic vectors i.v. at 2 days after tumor cell implantation and were followed for survival. Data are expressed as the percentage of survival over time. The groups included AdIL2, AdIL12, the AdCD control virus, and naive controls. 


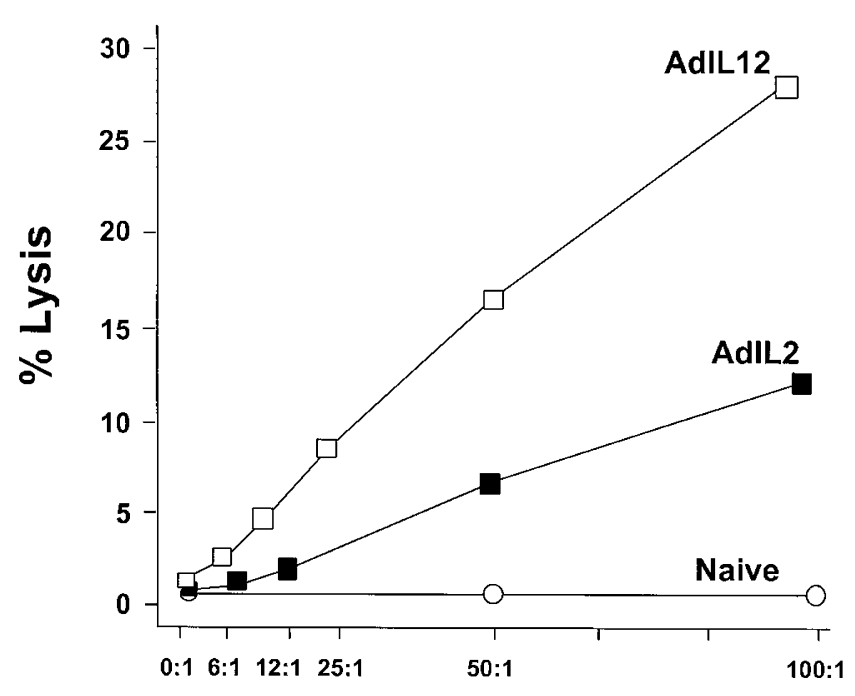

Effector:target ratio

Figure 4. Assessment of tumor-specific CTLs after treatment of hepatic micrometastases. Tumor-bearing mice were treated with AdIL2 or AdIL12 at 2 days after tumor cell implantation; animals receiving no therapy served as a control. Splenocytes were isolated at 12 days after vector delivery and stimulated in vitro with $\gamma$-irradiated C26 cells for 5 days. The cultured splenocytes were evaluated for specific lysis against C26 tumor cells in a cytotoxicity assay. Each datapoint represents the percentage of specific lysis of pooled lymphocytes from three animals. Data are expressed as the percentage of specific lysis at various E:T cell ratios.

\section{NK activity after AdIL2 and AdIL12 delivery}

To assess the ability of AdIL2 and AdIL12 to induce NK cell activity in vivo, naive (non-tumor-bearing) splenocytes from mice that had received a single dose of AdIL2, AdIL12, or control virus were evaluated for the percentage of specific lysis of the NK-specific target cell YAC-1 (Fig 5). AdIL12 delivery induced marked NK cell activity. AdIL2 also induced NK activity, but to a much lesser extent.

\section{DISCUSSION}

Based on the well-established antitumor profile of IL-2 and IL-12 cytokine therapy, ${ }^{2,28}$ the current study explores the potential of delivering the cDNAs of these two cytokines to the hepatic parenchyma to act as a regional therapy for hepatic metastases. Capitalizing on the fact that i.v. delivery of Ad vectors delivers $>90 \%$ of the Ad genome to the liver, ${ }^{43,44}$ the IL-2 and IL-12 cDNAs were delivered to the livers of $\mathrm{BALB} / \mathrm{c}$ mice using an Ad vector as an experimental regional therapy for established hepatic micrometastases derived from the syngeneic colon cancer cell line C26. The data show that i.v. delivery of AdIL2 and AdIL12 yields significant levels of each cytokine within the hepatic parenchyma, with no concomitant increase in sera levels. Therapeutically, both vectors are capable of reducing tumor

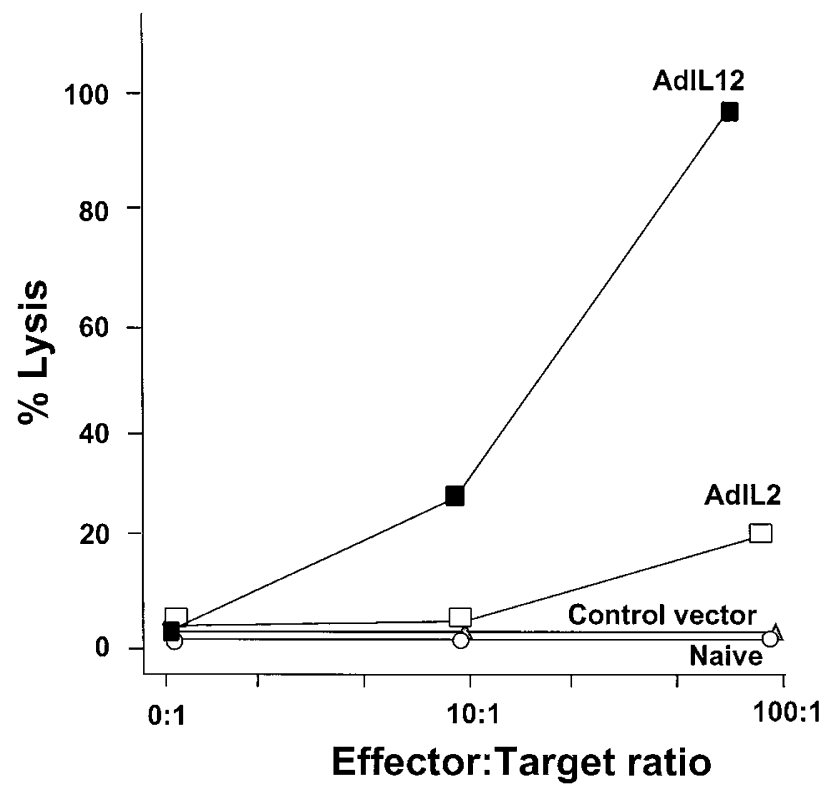

Figure 5. Assessment of NK activity after administration of AdlL2 and AdIL12. Non-tumor-bearing mice received a single dose of AdIL12, AdIL2, or control virus or received no therapy. On day 7, splenocytes were assessed for their ability to lyse the NK-specific target cell YAC-1 using a cytotoxicity assay. Data are expressed as the percentage of specific lysis at various E:T cell ratios. Each datapoint represents the percentage of specific lysis of pooled lymphocytes from three animals.

burden in the liver by a significant margin. In addition, both therapies yielded a significant survival advantage by log-rank analysis, although only AdIL12 treatment translated into a increase in mean survival. The mechanisms of antitumor effect of both vectors are associated with the generation of tumor-specific cytotoxic $\mathrm{T}$ cells as well as NK cell activity. The relative increase in cellmediated immunity (both T-cell and NK activity) associated with AdIL12-treated animals compared with AdIL2-treated animals in these in vitro assays suggests a therapeutic advantage of AdIL12 therapy, although these in vitro differences were not reflected in the relative suppression of tumor growth. However, these data could help to explain the relative increase in mean survival after AdIL12 therapy compared with AdIL2 therapy.

In vivo Ad-mediated cytokine regional expression in hepatic parenchyma

Cytokine therapy for cancer is intended to direct host immunity to tumor cells. ${ }^{1}$ Serial administrations of recombinant cytokines have been used experimentally and clinically with some therapeutic success, but also with unwanted systemic toxicity resulting from supranormal circulating levels of cytokines following high dose bolus delivery or the narrow therapeutic index of sustained infusion. ${ }^{23-25,28-30,43,48,49}$ Gene therapy is a strategy in which cytokines can be produced at sustained doses in a paracrine fashion and localized to the site organ of the 
tumor. ${ }^{1,3-19,50-54}$ Ex vivo gene therapy vaccine strategies use cytokine gene-modified tumor (or normal) cells to enhance host immunity at the site of the tumor cells and at tumor foci at distant sites. ${ }^{50-54}$ In vivo strategies target tumor cells in situ, without having to modify cells ex vivo. In vivo gene therapy has been carried out using IL-2 and IL-12 cDNAs in experimental tumor models. ${ }^{5-19}$ This approach strives to enhance the immune recognition of tumor cells at the site of the primary tumor and may induce systemic antitumor immunity that is effective at distant sites. ${ }^{6,10}$

The current study evaluates the use of in vivo cytokine gene therapy for microscopic metastases localized within a single organ. However, the approach is different from that used in prior studies. ${ }^{5-19}$ Rather than directing the gene therapy to the tumor mass, the gene therapy is directed toward the organ overall. Regionally directed in vivo gene therapy offers an approach to treat microscopic disease without having to target tumor cells directly. Experimentally, regional delivery to the hepatic parenchyma of small animals using Ad vectors can be accomplished by intravenous, intraportal, or intrahepatic arterial injection of vector. ${ }^{42-44,55}$ Importantly, there is minimal risk from the Ad vector per se, with systemic (i.v.) administration of $\leq 10^{9}$ PFU Ad vectors to mice inducing only mild, self-limited inflammation within the hepatic parenchyma. ${ }^{20}$ Although it is possible that the inflammatory mediators associated with $\mathrm{Ad}$ vector infection per se (not measured in these studies) might contribute to the therapeutic effects seen with AdIL2 and AdIL12 administration, Ad vector-mediated inflammation is unlikely to play a significant role; Ad vector alone (at $10^{8} \mathrm{PFU}$ ) had no independent therapeutic effect. Comparisons of the efficacy and toxicity of this therapy to that of systemically administered cytokines remain to be evaluated. Another strategy of locally administered gene therapy to the normal liver parenchyma includes the hepatic delivery of the gene for the prodrug $\mathrm{CD} .^{20,42}$

\section{Survival and induction of systemic immunity}

The potential for the induction of systemic antitumor immunity after in vivo regional therapy of AdIL2 or AdIL12 for micrometastases is suggested by the finding of specific CTLs directed against parental tumor cells in vitro. The induction of NK cells by AdIL12 and to a lesser extent AdIL2 that was observed after i.v. delivery of these vectors may offer systemic antitumor immunity in an MHC class I-independent fashion. However, it can be seen through survival experiments that in vivo antitumor immunity after a single dose of these Ad vectors is insufficient to effect a cure in this model. Although both therapies show a significant survival advantage by log-rank analysis and a similar reduction of tumor burden at 2 weeks, it is unclear why there is a discrepancy between the mean survival advantage seen in AdIL12-treated animals and the advantage seen in AdIL2-treated animals. One explanation is that the measurement of tumor area at 2 weeks may not reflect actual differences in viable cell number within the hepatic tumors; fewer viable cells present within the AdIL12-treated tumors would lead to a significant delay of the growth curve of these tumors, and thus mortality, when compared with AdIL2-treated mice and controls. Alternatively, IL-12 expression may induce or potentiate lasting immunity through its effects on antigen-presenting cells and $\mathrm{T}$ helper 1 cells, which are important in maintaining immune memory. ${ }^{2}$ In contrast, IL-2, whose antitumor effects are thought to result from direct stimulation of effector cells, acts to bypass rather than augment these mechanisms of cellular immunity. ${ }^{34,37} \mathrm{~A}$ combination of these two cytokines is logical and has been shown to augment the antitumor effects of either cytokine alone..$^{56,57}$ This combination may offer further significant antitumor immunity through increases in effector cell number and function and remains to be explored using a regional in vivo approach. The current study nonetheless offers an additional approach for local control of tumors, with the potential for systemic immunity; further benefit may be gained experimentally with less aggressive and more immunogenic tumor cell lines and potentially with primary tumors in a clinical setting.

\section{ACKNOWLEDGMENTS}

We thank N. Mohamed for help in preparing this manuscript. These studies were supported in part by the National Institutes of Health/National Heart, Lung, and Blood Institute (R01 CA 75192 and R21 CA 75153), the Will Rogers Memorial Fund (Los Angeles, Calif), and GenVec, Inc. (Bethesda, Md).

\section{REFERENCES}

1. Pardoll DM. Paracrine cytokine adjuvants in cancer immunotherapy. Annu Rev Immunol. 1995;13:399-415.

2. Lanzavecchia A. Identifying strategies for immune intervention. Science. 1993;260:937-944.

3. Tepper RI, Mule JJ. Experimental and clinical studies of cytokine gene-modified tumor cells. Hum Gene Ther. 1994;5:153-164.

4. Gilboa E. Immunotherapy of cancer with genetically modified tumor vaccines. Semin Oncol. 1996;23:101-107.

5. Haddada H, Ragot T, Cordier L, et al. Adenoviral interleukin-2 gene transfer into p815 tumor cells abrogates tumorigenicity and induces antitumoral immunity in mice. Hum Gene Ther. 1993;4:703-711.

6. Addison CL, Braciak T, Ralston R, et al. Intratumoral injection of an adenovirus expressing interleukin 2 induces regression and immunity in a murine breast cancer model. Proc Natl Acad Sci USA. 1995;92:8522-8526.

7. Chen SH, Chen XH, Wang Y, et al. Combination gene therapy for liver metastasis of colon carcinoma in vivo. Proc Natl Acad Sci USA. 1995;92:2577-2581.

8. Cordier L, Duffour MT, Sabourin JC, et al. Complete recovery of mice from a pre-established tumor by direct intratumoral delivery of an adenovirus vector harboring the murine IL-2 gene. Gene Ther. 1995;2:16-21.

9. Hurford RK Jr, Dranoff G, Mulligan RC, et al. Gene therapy of metastatic cancer by in vivo retroviral gene targeting. Nat Genet. 1995;10:430-435.

10. Bramson JL, Hitt M, Addison CL, et al. Direct intratu- 
moral injection of an adenovirus expressing interleukin-12 induces regression and long-lasting immunity that is associated with highly localized expression of interleukin-12. Hum Gene Ther. 1996;7:1995-2002.

11. Caruso M, Pham-Nguyen K, Kwong YL, et al. Adenovirusmediated interleukin-12 gene therapy for metastatic colon carcinoma. Proc Natl Acad Sci USA. 1996;93:11302-11306.

12. Huang H, Chen SH, Kosai K, et al. Gene therapy for hepatocellular carcinoma: long-term remission of primary and metastatic tumors in mice by interleukin-2 gene therapy in vivo. Gene Ther. 1996;3:980-987.

13. Qin H, Chatterjee SK. Recombinant vaccinia expressing interleukin-2 for cancer gene therapy. Cancer Gene Ther. 1996;3:163-167.

14. Toloza EM, Hunt K, Swisher S, et al. In vivo cancer gene therapy with a recombinant interleukin-2 adenovirus vector. Cancer Gene Ther. 1996;3:11-17.

15. Bui LA, Butterfield LH, Kim JY, et al. In vivo therapy of hepatocellular carcinoma with a tumor-specific adenoviral vector expressing interleukin-2. Hum Gene Ther. 1997;8: 2173-2182.

16. Chen L, Chen D, Block E, et al. Eradication of murine bladder carcinoma by intratumor injection of a bicistronic adenoviral vector carrying cDNAs for the IL-12 heterodimer and its inhibition by the IL-12 p40 subunit homodimer. J Immunol. 1997;159:351-359.

17. Levraud JP, Duffour MT, Cordier L, et al. IL-2 gene delivery within an established murine tumor causes its regression without proliferation of preexisting antitumorspecific CTLs. J Immunol. 1997;158:3335-3343.

18. Pützer BM, Hitt M, Muller WJ, et al. Interleukin 12 and B7 costimulatory molecule expressed by an adenovirus vector act synergistically to facilitate tumor regression. Proc Natl Acad Sci USA. 1997;94:10889-10894.

19. Pützer BM, Bramson JL, Addison CL, et al. Combination therapy with interleukin-2 and wild-type p53 expressed by adenoviral vectors potentiates tumor regression in a murine model of breast cancer. Hum Gene Ther. 1998;9:707718.

20. Ohwada A, Hirschowitz EA, Crystal RG. Regional delivery of an adenovirus vector containing the Escherichia coli cytosine deaminase gene to provide local activation of 5-fluorocytosine to suppress the growth of colon carcinoma metastatic to liver. Hum Gene Ther. 1996;7:15671576.

21. Willett CG, Tepper JE, Cohen AM, et al. Failure patterns following curative resection of colonic carcinoma. Ann Surg. 1984;200:685-690.

22. Ballantyne GH, Quin J. Surgical treatment of liver metastases in patients with colorectal cancer. Cancer. 1993;71: 4252-4266.

23. Rosenberg SA, Lotze MT, Muul LM, et al. A progress report on the treatment of 157 patients with advanced cancer using lymphokine-activated killer cells and interleukin-2 or high-dose interleukin-2 alone. $N$ Engl J Med. 1987;316:889-897.

24. Lee RE, Lotze MT, Skibber JM, et al. Cardiorespiratory effects of immunotherapy with interleukin-2. J Clin Oncol. 1989;7:7-20.

25. Margolin KA, Rayner AA, Hawkins MJ, et al. Interleukin-2 and lymphokine-activated killer cell therapy of solid tumors: analysis of toxicity and management guidelines. J Clin Oncol. 1989;7:486-498.

26. Dalgleish AG. The role of IL-2 in gene therapy. Gene Ther. 1994;1:83-87.

27. Orange JS, Salazar-Mather TP, Opal SM, et al. Mecha- nism of interleukin 12-mediated toxicities during experimental viral infections: role of tumor necrosis factor and glucocorticoids. J Exp Med. 1995;181:901-914.

28. Brunda MJ, Luistro L, Rumennik L, et al. Antitumor activity of interleukin 12 in preclinical models. Cancer Chemother Pharmacol. 1996;38:S16-S21.

29. Lamont AG, Adorini L. IL-12: a key cytokine in immune regulation. Immunol Today. 1996;17:214-217.

30. Leonard JP, Sherman ML, Fisher GL, et al. Effects of single-dose interleukin-12 exposure on interleukin-12-associated toxicity and interferon- $\gamma$ production. Blood. 1997; 90:2541-2548.

31. Zitvogel L, Lotze MT. Role of interleukin-12 (IL12) as an anti-tumour agent: experimental biology and clinical application. Res Immunol. 1995;146:628-638.

32. Trinchieri G, Scott P. Interleukin-12: a proinflammatory cytokine with immunoregulatory functions. Res Immunol. 1995; 146:423-431.

33. Fujiwara H, Zou JP, Herrmann S, et al. A sequence of cellular and molecular events involved in IL12-induced tumour regression. Res Immunol. 1995;146:638-644.

34. Fearon ER, Pardoll DM, Itaya T, et al. Interleukin-2 production by tumor cells bypasses $\mathrm{T}$ helper function in the generation of an antitumor response. Cell. 1990;60: 397-403.

35. Colombo MP, Vagliani M, Spreafico F, et al. Amount of interleukin 12 available at the tumor site is critical for tumor regression. Cancer Res. 1996;56:2531-2534.

36. Rao JB, Chamberlain RS, Bronte V, et al. IL-12 is an effective adjuvant to recombinant vaccinia virus-based tumor vaccines: enhancement by simultaneous B7-1 expression. J Immunol. 1996;156:3357-3365.

37. Rodolfo M, Zilocchi C, Melani C, et al. Immunotherapy of experimental metastases by vaccination with IL genetransduced adenocarcinoma cells sharing tumor-associated antigens: comparison between IL-12 and IL-2 genetransduced tumor cell vaccines. J Immunol. 1996;157: $5536-5542$.

38. Hirschowitz EA, Leonard S, Song W, et al. Adenovirusmediated expression of melanoma antigen gp75 as immunotherapy for metastatic melanoma. Gene Ther. 1998;5: $1-9$.

39. Bramson J, Hitt M, Gallichan WS, et al. Construction of a double recombinant adenovirus vector expressing a heterodimeric cytokine: in vitro and in vivo production of biologically active interleukin-12. Hum Gene Ther. 1996;7: 333-342.

40. Hirschowitz EA, Ohwada A, Pascal WR, et al. In vivo adenovirus-mediated gene transfer of the Escherichia coli cytosine deaminase gene to human colon carcinoma-derived tumors induces chemosensitivity to 5-fluorocytosine. Hum Gene Ther. 1995;6:1055-1063.

41. Rosenfeld MA, Yoshimura K, Trapnell BC, et al. In vivo transfer of the human cystic fibrosis transmembrane conductance regulator gene to the airway epithelium. Cell. 1992;68:143-155.

42. Topf N, Worgall S, Hackett NR, et al. Regional "prodrug" gene therapy: intravenous administration of an adenoviral vector expressing the $E$. coli cytosine deaminase gene and systemic administration of 5-fluorocytosine suppresses growth of hepatic metastasis of colon carcinoma. Gene Ther. 1998;5:507-513.

43. Herz J, Gerard RD. Adenovirus-mediated transfer of low density lipoprotein receptor gene acutely accelerates cholesterol clearance in normal mice. Proc Natl Acad Sci USA. 1993;90:2812-2816. 
44. Worgall S, Wolff G, Falck-Pedersen E, et al. Innate immune mechanisms dominate elimination of adenoviral vectors following in vivo administration. Hum Gene Ther. 1997;8:37-44.

45. Song W, Kong HL, Traktman P, et al. Cytotoxic T lymphocyte responses to proteins encoded by heterologous transgenes transferred in vivo by adenoviral vectors. Hum Gene Ther. 1997;8:1207-1217.

46. Decker T, Lohmann-Matthes ML. A quick and simple method for the quantitation of lactate dehydrogenase release in measurements of cellular cytotoxicity and tumor necrosis factor (TNF) activity. J Immunol Methods. 1988; 115:61-69.

47. Gately MK, Warrier RR, Honasoge S, et al. Administration of recombinant IL-12 to normal mice enhances cytolytic lymphocyte activity and induces production of IFN- $\gamma$ in vivo. Int Immunol. 1994;6:157-167.

48. Ardizzoni A, Bonavia M, Viale M, et al. Biologic and clinical effects of continuous infusion interleukin-2 in patients with non-small cell lung cancer. Cancer. 1994;73: 1353-1360.

49. Legha SS, Gianan MA, Plager C, et al. Evaluation of interleukin-2 administered by continuous infusion in patients with metastatic melanoma. Cancer. 1996;77:89-96.

50. Elder EM, Lotze MT, Whiteside TL. Successful culture and selection of cytokine gene-modified human dermal fibroblasts for the biologic therapy of patients with cancer. Hum Gene Ther. 1996;7:479-487.
51. Lotze MT, Rubin JT, Carty S, et al. Gene therapy of cancer: a pilot study of IL-4-gene-modified fibroblasts admixed with autologous tumor to elicit an immune response. Hum Gene Ther. 1994;5:41-55.

52. Sobol RE, Royston I, Fakhrai H, et al. Injection of colon carcinoma patients with autologous irradiated tumor cells and fibroblasts genetically modified to secrete interleukin-2 (IL-2): a phase I study. Hum Gene Ther. 1995;6:195204.

53. Tahara H, Zeh HJ III, Storkus WJ, et al. Fibroblasts genetically engineered to secrete interleukin 12 can suppress tumor growth and induce antitumor immunity to a murine melanoma in vivo. Cancer Res. 1994;54:182-189.

54. Zitvogel L, Tahara H, Robbins PD, et al. Cancer immunotherapy of established tumors with IL-12: effective delivery by genetically engineered fibroblasts. J Immunol. 1995;155:1393-1403.

55. Jaffe HA, Danel C, Longenecker G, et al. Adenovirusmediated in vivo gene transfer and expression in normal rat liver. Nat Genet. 1992;1:372-378.

56. Pappo I, Tahara H, Robbins PD, et al. Administration of systemic or local interleukin-2 enhances the anti-tumor effects of interleukin-12 gene therapy. J Surg Res. 1995;58: 218-226.

57. Vagliani M, Rodolfo M, Cavallo F, et al. Interleukin 12 potentiates the curative effect of a vaccine based on interleukin 2-transduced tumor cells. Cancer Res. 1996; 56:467-470. 